\title{
Transferring Academic Decision Models to Practitioners: A Structured Process
}

\author{
Michel Leseure \\ Isle of Man International Business School \\ The Nunnery, Douglas \\ IM2 1QB, Isle of Man \\ E-mail: m.leseure@ibs.ac.im \\ Hassan Atif \\ Office Cherifien des Phosphates \\ 2, Rue Al Abtal - Hay Erraha, Casablanca \\ 20 200, Morocco \\ E-mail : h.atif@ocpgroup.ma
}

\begin{abstract}
The decision support model presented in this paper is the result of a research project initiated by a large organisation operating in an emerging economy. The exotic business context of this company generated many reservations and questions about the applicability of traditional supply chain management models in terms of the decisions that should be made to design a supply chain. As supply chain management decisions are complex, decision makers often rely on approximate, ineffective decision making processes. Through a process rooted in decision analysis, this paper shows how apparently conflicting academic models of supply chain system design were successfully transferred, absorbed, customised, and used by the company.
\end{abstract}

\section{KEYWORDS}

Knowledge transfer, decision analysis, supply chain design, emerging economy.

\section{BIOGRAPHICAL NOTES}

Michel J. Leseure received a $\mathrm{PhD}$ in Manufacturing Management from the University of Sheffield (UK), an MBA from Eastern Washington University (USA), and an engineering diploma from ENSMM (France). He started his career as a mechanical engineer in the customized capital goods industry. He is now a Lecturer at the Isle of Man International Business School. Articles authored by Michel Leseure have appeared in journals such as the International Journal of Operations and Production Management, the International Journal of Technology Management, Omega, and the International Journal of Business Performance Management.

Hassan Atif holds an engineering diploma in mechanical engineering from Ecole Mohamedia d'Ingénieurs, Morocco, and an Executive MBA from Al Akhawayn University, Morocco. He has more than 10 years of business experience in maintenance management, supply management, and inventory management. He has supervised department ranging in size from 100 to 280 persons.

Please reference this paper as:

Leseure, M and Atif, H. (2010), "Transferring academic decision models to practitioners: a structured process”, International Journal of Applied Decision Science, Vol. 3, No. 1, pp. 74-89. 


\section{Introduction}

How often do companies voluntary engage in a review of the academic literature to find solutions to the problems they face? The cherished academic tradition of a literature review can hardly be described as a standard industrial practice. As a matter of fact, students engaged in a dissertation process often voice concern about the difficulty of conducting a literature review, and research shows that there is a lot of ambiguity regarding the perception of what a literature review is, and how it should be done (Bruce, 1994, 2001). The author's personal experience is that concerns over the relevance and usefulness of literature review are even more vibrantly expressed in the case of MBA students, or in the case of other students engaged in action research dealing with management studies. The purpose of this paper is to present a procedure through which a company actually learnt from a literature review, and developed from it a conceptual decision model, which was tested, and later, implemented in the company. As such it illustrates an explicit to tacit transfer of knowledge from academia to practitioners. More importantly, the paper illustrates a structured process through which this process can be replicated.

The paper is organised as follows. The first section describes the context of the case study. The second section describes the structured process. The third section describes the literature review and its critical conclusions. The fourth section describes the output of the process, i.e. the decision model, and its testing. The final section is a discussion of the case experience.

\section{Context of the Case Study}

The case company is a large mining company based in North Africa. A specificity of this company is to sell all of its output in international markets, and therefore to compete globally while operating in an emerging economy.

Its main challenge is that its local economic environment does not provide a reliable set of suppliers to which activities can be subcontracted. It is in this context that the project was initiated, with the objective of identifying (1) what guidelines could be used to select activities to be outsourced, and (2) how to manage outsourcing while maintaining current performance levels.

From these initial project specifications, three key hurdles were identified:

- When companies question the design of their supply chain management system, they often do so on an incremental basis. After an initial literature review, it was found that there was no model that addressed the problem of historically heavily vertically integrated companies. In industrialised economies, the shift from vertically-integrated giants to today's "extended" enterprises (Boardman and Clegg, 2001) has been gradual and the result of a long chronology of incremental decisions.

- This implies that supply chain management best practices tend to be observed, studied, and documented in specific contexts or epochs. When put under the test of several well-know supply chain management models, the activities of the case company yielded paradoxical recommendations: the same activity should be internalised according to one model whilst it should be outsourced according to another one. 
- In managers' minds, the decision to outsource an activity, the choice of a coordination mechanism, and purchasing management issues are often combined in one single, "block" decision, i.e. the three decisions are made at the same time. In the context of the case company, such a "block" decision appeared so risky to managers that most preferred to keep activities in-house.

It is worth stressing that similar challenges exist in more industrialised economies. For example, it is difficult to explain why a company like Honda made the decision to invest in engines and power trains as core competencies whilst Chrysler made the decision to outsource these components (Hamel and Heene, 1994; Prahalad and Hamel, 1990). It is with these three hurdles and paradoxes in mind that the research project was redefined as the design of a decision model supporting supply chain management system design activities. More specifically, the project objectives were:

1. To address the issue of corporate activity management in its entirety, i.e. to provide a mean to integrate incremental outsourcing decisions into one unique, adaptable, management system.

2. To be context and time dependent in order to make clear, non-paradoxical recommendations. The model should allow retrospective sense making (Weick, 1979), i.e. it should evolve as lessons about preceding initiatives are learnt and assimilated.

3. To integrate into one cohesive whole traditional supply chain management system design models.

4. To structure the various decisions about supply chain management system design into a sequence of well-defined decisions to avoid the logical ambiguity of "block" decisions.

\section{The Structured Process}

To cope with the unusual context of the research, the following process was used:

\section{Stage 1: Literature Review with Problem Structuring.}

As preliminary work showed that standard supply chain decision models were not adapted to the context of the case company, a literature review was initiated to provide a larger picture of supply chain system design issues. Its purpose was to learn from the literature and to generate a relevant starting point for the company to make decisions.

In terms of decision making, the authors felt that the problem was "the process, not the product" (Grum and Hesse, 1983). In other words, various supply chain management theories are not erroneous or conflicting, but it is the process, or rather, the lack of process when applying them, that can lead to erroneous or paradoxical recommendations. This is a well known problem in decision science, and thus, it was decided that the research work should be based on decision analysis tools and techniques. As a result, the literature review was implemented in an innovative way, as every single paper was summarised as an influence diagram. Influence diagrams are a graphical convention used to represent the structural relationships between decisions, decision variables, parameters, and uncertain variables. Their purpose is to summarise influence relationships, e.g. decision parameter " $\mathrm{A}$ " influence decision "X" (Clement and Reilly, 2001). The requirement to summarise each reviewed paper is the pivotal stage of the knowledge transfer process. It is from a collection of 
structured decision models represented according to a unique "grammar" that a synthetic decision model, customised to the case of the company, was developed.

\section{Stage 2: Integrative Supply Chain System Design Decision Model}

A general design model was assembled from the influence diagrams prepared during the literature review. This was the inductive part of the research project.

\section{Stage 3: In-situ application and testing of the model}

Data used in the testing of the model was gathered over a period of 8 months through numerous field interviews and meetings, either with individuals, groups, or entire corporate units. As the project was an Executive MBA final dissertation where the second author rotated 4 weeks at the university and 2 weeks at work, there were ample opportunities for interviewing, testing, and running pilot projects. The model was tested fully on three activities, meaning that the influence diagrams built in stage 2 were populated with real business scenarios, cost data, and weights provided by the group meetings. The part of the model requiring a test on a portfolio of activities was tested with all maintenance activities at one of the sites of the company.

\section{Critical Literature Review}

\subsection{Review Method}

The literature review was conducted early in 2002 and availability of papers was an issue. Thus, no claims are made that the literature review was exhaustive. Instead, limited access to academic sources, either because of limited resources or lack of time, was a limiting factor. For practitioners trying to learn from a review of the academic literature, it is not an usual set of circumstances. Bearing in mind this limitation, the emphasis in this project was to design a robust method of absorbing academic knowledge.

The literature review consisted in drawing, for each reviewed work on supply chain management, an influence diagram representing the implicit structure of the decision model suggested by the authors. The traditional graphical convention for influence diagrams is used (Clemen and Reilly, 2001):

- Rectangle boxes indicate decisions to be made;

- rounded rectangle boxes indicate numerical constants or computed values;

- ellipses indicate a chance event, i.e. an event whose outcome cannot be fully controlled by the decision maker;

- lozenge represents the final consequence, or pay-off, of a decision; and

- arcs have a variety of meanings implied by their context. They can indicate precedence, relevance, or a relationship between two nodes.

\subsection{Results}

Figure 1 displays the results of the literature review. These results confirm that the literature does not form a cohesive whole. Different papers exhibit: (1) different decision objectives, (2) decisions of different scopes, (3) the use of different decision variables, and (4) different decision making sequences. 
It was possible, however, to classify the reviewed papers in five categories. The first category groups all decision models based on a production economics view of the firm, based on the transaction cost theory of Williamson $(1975,1985)$. In these models, the decision objective is to minimise transaction costs, i.e. the cost incurred in the management and administration of a transaction between two firms. The decision to be made is a governance structure decision, which embeds the decision to outsource an activity and the decision about a mode of governance. A number of other studies have expanded, refined, or revised the work of Williamson (Shary and Skjott-Larsen, 2001; Dyer, 1996; Cox, 1996, 1997). These studies focus on the parameters of the decision (e.g. how to define asset specificity in practice), but they do not criticise the structure of the decision model of Williamson.

The second category of models is based on the core competency view of the firm of Prahalad and Hamel (1990). These decision models shift the emphasis from an economics view of the firm towards business strategy. This approach is also consistent with the resource-based view of the firm. In terms of decision scope, the focus of these models is the outsourcing decision solely (Barney, 1991; Grant, 1991; Collis, 1991; Welch and Nayack, 1992).

The third category groups typological models, i.e. models which suggest that supply chain management decisions are so diverse and context sensitive that some form of classificatory scheme should be used to make better decisions. Wickham (1996) proposes a model based on a preliminary classification of activity feeding a model including outsourcing and governance decision. Saunders introduces the notion of a portfolio of outsourcing activities and decisions, and suggests that different parts of the portfolio should be managed differently (1997). His decision model includes the outsourcing decision and a purchasing strategy decision corresponding to the governance decision of Williamson. Saunders is one of the only models dealing with a portfolio of decisions and that proposes a truly "multi-channel" decision making process.

The fourth category groups all models that attempt some form of integration of the various schools of thoughts. The objective of these studies is to provide an outsourcing framework for practitioners. These models are often articulated around the traditional managerial accounting notion of a make or buy decision (Probert, 1996; Canez el al., 2000; Fill and Visse, 2000; Mc Ivor, 2000; Grosse et al., 2001).

Finally, the last category includes models that were designed for specific contexts. In the engineered-to-order industry, Venkatesan (1992) bases outsourcing decisions on a performance benchmark between the firm and its potential suppliers, and provides an unusual decision objective: improving employee's commitment to performance. Daval proposes a decision model for the spin-off process as a form of outsourcing (2000). Finally, Julien, Jacob, and Raymond (1998) report best practices in terms of managing a network of small enterprises working for a large pivot firm. It is noteworthy that these specific models are amongst the few that go beyond the decision to outsource and include some decision about designing and managing the supply chain. 


\subsection{Critical Analysis}

From a decision analysis perspective, the models reviewed in the literature present a number of flaws:

- Many are based on embedded, "block", decisions, i.e. they make several subdecisions in one step. Embedded decisions are symptomatic of a set of complex decisions that are not clearly structured in the mind of decision makers. Even the model of Fill and Visse (2000), which is based on decision science techniques, displays a lack of structure as it turns out to be only a multi-attribute scoring model.

- Unequal weights are given to several decisions. The decision to outsource is usually at the forefront of all models, whereas decisions related to the organisation and the structuring of the supply chain system are overlooked.

- Most models are designed to conduct a reflection activity by activity. Only a few (Saunders, 1997; Julien et al., 1998) have for scope the management of a portfolio of outsourced activities.

- There is some ambiguity regarding the objectives that drive supply chain management decisions. An ideal model should integrate the fact that multiple objectives are present and should provide means to balance them. This shortcoming is diagnosed and addressed by the decision model of Fill and Visse (2000).

\section{Supply Chain Management Design Model}

\subsection{Methodology for Synthesis}

To overcome the limitations presented above, a decision model was built by structuring the various decision models reviewed in the literature. The building of the model followed four steps: (1) the definition of the decisions objectives, (2) the structuring of the chain of decisions in supply chain management system design, (3) the elaboration of detailed influence diagrams for each decision, and (4) the development of a master influence diagram. The overall objective of the model building stage was to produce a synthetic decision model with a maximum compatibility with the original models shown in figure 1 .

A key challenge of generating a synthesis of a diverse set of research papers is that there are little guidelines available for researchers to handle conflicts and paradoxes amongst a large collection of research works. This is unfortunate as it may lead researchers to dismiss non congruent and inconsistent pieces of work. Doing so undermines the value of a literature review, as it is precisely in the ability to resolve conflicts and paradoxes that a literature review contributes to expanding a knowledge base. Poole and Van de Ven (1989) identify four different modes of working with paradoxes in order to build management and organisation theories.

- Opposition: Accept the paradox and use it constructively. In this scenario, researchers have to live with the paradox. Although the inclusion of a theory is inconsistent with the congruent set of a review, another perspective is presented in order to create a source of inspiration for theories from the opposition of viewpoints.

- Spatial Separation: Clarify levels of analysis. The paradox can be simply explained by highlighting that two theories operate at a different level of 
analysis. Poole and Van de Ven give the examples of the part-whole, micromacro, and individual-society.

- Temporal Separation: take time into account. A theory which was tested at one point in time may not hold true later on.

- Synthesis: Introduce new terms to resolve the paradox. This is a superior form of knowledge creation, where two conflicting theories are replaced by one unifying theory.

The shortcomings associated with the reviewed decision models were addressed as follows:

- "Block" decisions. This is a spatial separation problem resolved by the identification of distinct sub-decisions which should not be merged.

- Most models are designed to conduct a reflection activity by activity. This again is a spatial separation problem, and each decision step should be clearly labelled as focusing on activities or a portfolio of them.

- There is some ambiguity regarding the objectives that drive supply chain management decisions. An ideal model should integrate the fact that multiple objectives are present and should provide means to balance them (e.g. through a MAUT function). Thus, in this case, the opposition principle was adopted.

- There are considerable variations regarding the sequence in which decisions are made, and the timing with which they are made. Managerial shorttermism for example, could be explained by the inclusion of cost data too early in the decision sequence. This is a problem of temporal separation, and the notion of co-ordination requirements trajectory was introduced to address this issue.

\subsection{Model Description}

Figure 2 shows that final model after completion of the synthesis stage.

\section{(( Take in figure 2 here))}

Designing and organising a supply chain management system involves a chain of decisions presented in the macro decision chain shown in the top left corner of figure 2. Key specifications of this decision chain are that:

- When an outsourcing decision is made, it is made for one activity, independently of the set of activities currently internalised and outsourced. The decision is also made without any notion of the mechanisms through which it is eventually going to be outsourced. These considerations are "postponed" to a later stage.

- It is only once the decision to outsource has been made that managers have to address implementation. A parallel can be drawn with the separation principle in corporate finance, where, in the most general case, the investing and financing decisions are made independently of each other.

- The following stage is to consider the portfolio of decisions made regarding outsourcing to decide how to design or modify the supply chain management system of an organization.

- It is only once a clear system design has been formulated and agreed upon that purchasing procedures for each type of activity can be defined. 
The ultimate decision objective of the model is to enhance competitiveness. The lozenge on the top right corner of figure 2 presents the most general formulation of the various sub-objectives derived from the literature review.

The other diagrams in figure 2 provide a detailed view of each of the decision in the decision chain.

The first step of the model is the outsourcing decision. The team concluded that the outsourcing decision is primarily strategic, and hence, most traditional variables used here (cost, supply base) should instead be used at a later stage. Next, the question is to determine through which mechanisms outsourcing should be planned and implemented: subcontracting typically requires little co-ordination efforts; whereas spin-offs, partnerships, and networks typically require important co-ordination means and efforts. An influence diagram is used to assess and document the coordination requirements for each activity.

At this stage, managers have assessed the strategic role of the activity and its coordination requirements. Managers should then position the current and ideal positions of the activity on a strategic role/coordination matrix shown at the bottom left of figure 2 .

Co-ordination trajectory mapping is an important step to stress out that the selected outsourcing mechanisms may be temporary. For instance, a collaborative supply network will necessitate permanent co-ordination efforts, whereas a spin-off may involve high collaboration and support initially and will gradually evolve to a simple subcontracting relationship.

Once managers have agreed upon a trajectory, the next step is to validate its financial feasibility, which then leads to the selection of a governance mode, as shown in the "Governance Decision" influence diagram. At this stage, it is possible that the decision will be to keep an activity internally or to wait for a better timing due to budgetary constraints.

Whereas the previous decisions were made about individual activities, designing the supply chain system requires decisions considering the entire portfolio of outsourced activities. Therefore, the input of system design decisions is the aggregation of all the outsourcing tactics defined by the governance decisions. By aggregating all the outsourcing requirements it is facing, a company can summarise the demand put on its supply chain management system, and design it from there. The first decision is clustering, i.e. the classification of the different archetypes of activities into distinct clusters, using their outsourcing requirements and characteristics as classificatory variables. The second decision is "tiering", i.e. the decision regarding the management (or non management) of remote, indirect suppliers. This can be done for example through constraints imposed on the first tier, or through the creation of a community "network". Once the set of suppliers has been structured, organisational decisions can be made: the objective here is primarily to organise and structure supply chain management operations. For example, the clusters could correspond to different organisational sub-units. 
The last set of decisions consists in determining the appropriate form of relationship with suppliers from an administrative purchasing perspective. It constitutes the operational implementation of all decisions made previously. These decisions result primarily in procedures, each procedure targeting a different tier of suppliers, as determined at the previous stage. Once procedures are finalised, it is then possible to organise the purchasing function.

\subsection{Model Testing}

The application of the model is illustrated through two examples taken from the company for which the model was developed. The first is about a specific activity, the maintenance of diesel engines. Its purpose is to illustrate the first part of the model (outsourcing and governance decisions). The second example considers a larger set of activities and is used to illustrate the system design decision stage.

\subsubsection{Outsourcing and Governance Decisions Illustration}

The maintenance of diesel engines is strongly integrated. It involves 80 permanent employees who have all been trained from within the organization. This activity consists in overhauling, repairing, and testing engines and all their subsystems. The characteristic of this activity resides in the size of these engines, as the installed power reaches 1600 horsepower. Annual production output reaches 140 engines and more than 1000 subsystems.

In the emerging economy in which the company operates, the supply base for this service does not exist. This is due to the uniqueness of the equipment utilised in the company's specific mining process. Even other mines within the same country do not own engines of such capacity. From past experiences executives have preferred to retain this activity internally, mainly for three reasons:

- Time responsiveness, as this activity is crucial and affects directly the extraction process. Executives believe that only the hierarchical governance structure could ensure the required level of performance.

- Through many trials within the currently available suppliers, it has been established that the costs of outsourcing were higher than internal production costs. This can be explained by the lack of expertise within newly created businesses. This kind of activity requires long years of learning and without a strong corporate support it would be impossible to master it.

- Another reason behind the difference in costs stems from spare parts procurement, which is better developed within the company than in the rest of the country. Also the quantities of spare parts purchased in the group allow considerable price reductions.

- In this activity the physical assets investment is low in contrast to that in human assets. The activity is run at the appropriate level to benefit from economies of scale within the company.

A full decision model based on the outsourcing decision diagram was developed and used to run a meeting at the company. The meeting resulted in the decision that the diesel engine maintenance activity had a marginal strategic role, and that it should be outsourced. This decision was supported by a benchmark of all the direct international competitors of the company located in developed countries, who all outsource this activity. The next step was to determine the co-ordination requirements from the specific context of the company, characterised by the lack of a reliable supply base. The assessment, made in a similar fashion by building a multi- 
attribute score during a group meeting, resulted in a high-effort co-ordination requirement. This is explained by the following reasons: the asset is specific, the technology and skills complexity are relatively high (for the local context), and a national analysis of supply chain relationships reveals a situation of undependability and low trust. From this analysis, managers agreed that the only way to effectively outsource this activity was through a spin-off process which would secure the shift to external supplying through an initial phase of high support and coordination.

For the company, the outcome of the meeting was commented as "extremely enlightening". Whether or not the diesel maintenance activity should be outsourced had been a contentious topic for several years, and participants agreed that the method was truly superior in terms of helping them to make a decision.

\subsubsection{System Design Decision Illustration}

The analysis made above was generalised to all key maintenance activities at one site of the company. This choice was motivated by the abnormally high proportion of maintenance work done in house when comparing the company to its international competitors. The different maintenance activities were positioned on the strategic role/co-ordination matrix in order to classify them into key clusters, as shown in figure 3. Each of the clusters forms a natural supply chain system channel which should be managed differently.

\section{$(((($ Insert figure 3 here $))))$}

Cluster A groups activities presenting medium to high strategic role. These activities are crucial for the viability of the company. Even in a future more developed market, this category ought to be carried out internally. The coordination requisite is relatively high for this category. In case of a demand peak, capacity subcontracting should be undertaken on an intensified relationship basis.

Cluster B groups activities with low strategic role but that require specific needs for co-ordination. Unlike the preceding category for which activity demand is random, this cluster of activities can be planned over time. This cluster is deemed to be outsourced either on an immediate basis (if the market provides beneficial production costs), or on a medium to long-term basis (in case the domestic market requires more time to mature). For this cluster, accompanying measures are needed, either in the form of keeping the activity internal for a while, or using a spin-off process, or relying on partnering agreements.

Cluster $\mathrm{C}$ contains activities that present no strategic role and for which the market provides more competitive services in terms of costs and quality as of today.

For the company, this analysis confirmed the desirability to develop its supply chain management function with more competencies in terms of coordination, in order to complement the company's existing purchasing function. The importance of cluster $\mathrm{B}$ reinforced the past decision of the company to invest in local regional economic development, and to attach these tasks to the supply chain management function.

\section{Managerial Evaluation}


The model was repeatedly used in meetings. During these meetings, rhetoric arguments about what mining core competencies were, and the extent to which supply chain management was relevant to the company's case, were systematic occurrences. These discussions were not surprising as they had been common issues in the five years preceding the project. The use of influence diagrams was an extremely effective way of dealing with these disagreements. In all the cases when a group meeting was running the risk of being aborted as the purpose of the meeting was challenged, a discussion of the working principle of influence diagrams helped. Sceptical participants were explained that they were allowed to be critical of the establishment of a supply chain management programme, but that they had to structure their reservations coherently in the language of structured decisions rather than as logically unsound opinions. In most cases, all participants left meetings agreeing on the outcomes of the meeting, and the desirability of thinking about supply chain management, despite their initial resistance.

\section{Directions for Future Research}

The underlying issues discussed in the case study are not dissimilar to the challenge of a research student faced with the (sometimes daunting) task of writing a literature review, or to that of health authorities reviewing the evidence for or against a treatment.

In the case company, the problem of designing a supply chain system was initially deemed difficult because of industrial context. Once the topic was validated as an academic project, it only became a bigger problem: there was "too much" written about the topic and most of what was written did not match the context of the case. For example, one could argue that should the same project had been done in 1975, there would have been much less controversy regarding which model to use and what to do.

In other words the fact that more information was available did not solve the problem and potentially made it worse! This is, in the context of the modern knowledge economy, an important point to reflect upon. Key technological leaps have been achieved in the knowledge economy:

- To increase the quantity of knowledge produced (for example, there are more academics publishing today than 30 years ago).

- Knowledge diffusions (electronic databases and electronic books).

- Search technologies (search engines, meta-searches, electronic citation structures).

The case discussed in this paper is just one example of what the real challenge of the knowledge economy is: it is not to produce more knowledge faster or to better search it, nor to disseminate it faster. The real challenge is to make sense of it, i.e. to learn something useful and practical from a much larger and diverse knowledge base that has ever been made available to a decision maker.

Similarly, Tranfield, Denyer, and Smart (2003) state that management researchers under-utilise the existing knowledge base and suggest that systematic literature reviews as a methodological solution. However, their conclusion is that the weak point of the method is that of integration, which is described under the label of metasynthesis. Similarly, in their attempt to learn from the literature about the adoption of 
best practices, Leseure et al. (2004) use a systematic literature review methodology and conclude that the biggest challenge is that of integration, i.e. of bringing all theories and findings together.

Examples of meta-synthesis, or of research problems requiring the use of metasynthesis, include:

- Thomas (2003) inductive analytical approach.

- Meta-analysis combined with narrative (e.g., Borkowski, 1996).

- Meta-synthesis (Denyer and Tranfield, 2006; Finfgeld, 2003; Sandelowski et al., 1998; Siau and Long, 2005).

- Using document structure mapping to generate suggestions (Chen, 1996).

- Using fields (selection, tine, hierarchy and sequence) to qualify information that has lost its connection with the carrier (Koniger and Janowitz, 1995).

This paper, like all the papers quoted above, is concerned with the feasibility and the process of summarising and synthesising knowledge from different sources into a sensible, consistent, and actionable whole. The contribution of this paper is to suggest that a fertile stream of future research is to improve the rigour and effectiveness of meta-synthesis processes by using decision analytical tools and problem structuring methods. One example, based on the use of influence diagrams to structure a management literature review is provided in this paper. Decision analytic metasynthesis methods would have implications in management research, heath research, information research, and related fields.

\section{Conclusion}

Practitioners seldom turn naturally to the writings of academics to inform their practice. Negative stereotypes of formality, rigour, jargons, and impracticality abound. This state of affairs contrasts with the expressed desire to produce research which is relevant and actionable (Denyer and Tranfield, 2006).

This paper illustrates how the use of influence diagrams allowed a company to develop a synthetic model of supply chain system design which (1) exhibits a maximum compatibility with the academic literature and (2) is customised for use in the specific context of the company. The approach described in this paper can be applied to any situations where practitioners have to develop complex decision models. The method is a practical, feasible way of implementing transfers of knowledge from the academic literature to the business world.

More generally, this paper proposes that there are today many knowledge domains where decision makers are "drowning in information, but thirsty for knowledge" (Koniger and Janowitz, 1995). The challenge is to structure lessons learnt through different methods and means in different contexts into robust, logically-specified models that are actionable by decision makers. This paper suggests that the quest for rigorous knowledge aggregation can be informed and facilitated by incorporating decision analysis and problem structuring methods in meta-synthesis methodologies.

\section{Acknowledgments}

The helpful and constructive comments of reviewers are gratefully acknowledged. 


\section{References}

Barney, J. ( 1991) 'Firm resources and sustained competitive advantage', Journal of Management, Vol. 17, pp. 99-120.

Boardman , J. and Clegg, B. (2001) 'Structured engagement in the extended enterprise', International Journal of Operations and Production Management, Vol. 21, Issue 5/6, pp. 795-811.

Borkowski, S. (1996) 'An analysis (meta- and otherwise) of multinational transfer pricing research', The International Journal of Accounting, Vol 31, No. 1, pp. 39-53.

Bruce, C. (2001) "Interpreting the scope of their literature reviews: significant differences in research students' concerns", New Library World, Vol. 102, pp. 158165.

Bruce, C. (1994) 'Research students' early experience of the dissertation literature review', Studies in Higher Education, Vol. 19, No. 2, pp. 217-230.

Canez, L., Platts, K. and Probert, D. ( 2000) 'Developing a framework for make-orbuy decisions', International Journal of Operations and Production Management, Vol. 20, pp. 1313-1330.

Chen, Z. (1996) 'Generating suggestions through document structure mapping', Decision Support Systems, Vol. 16, pp. 297-314.

Clemen, B. and Reilly, T. (2001) Making Hard Decisions, Belmont, California: Duxbury Press.

Collis, D. (1991) 'A resource-based analysis of global competition: the case of the bearings industry', Strategic Management Journal, Vol. 12, pp. 49-68.

Cox, A. (1996) 'Relational competence and strategic procurement management: towards an entrepreneurial and contractual theory of the firm', European Journal of Purchasing and Supply Chain Management, Vol. 2, pp. 57-70.

Cox, A. (1997) Business Success, Boston, MA: Earlsgate Press.

Daval H. (2000) 'L'externalisation d'activités chez Thomson : une application du modèle des ressources et compétences à l'essaimage', IX Conférence de l'A.I.M.S., Electronic Proceedings, Montpellier, 24-26 May.

Denyer, D. and D. Tranfield. (2006) 'Using qualitative research synthesis to build actionable knowledge base', Management Decision, Vol. 44 No. 2, pp. 213-227.

Dyer, J. (1996) 'How Chrysler Created an American Keiretsu', Harvard Business Review, July-August, pp. 42-56.

Fill, C. and Visse, E. (2000) 'The outsourcing dilemma: a composite approach to the make and buy decision', Management Decision, Vol. 38, pp. 43-50.

Finfgeld, D. (2003) 'Metasynthesis: the state of the art - so far', Qualitative Health Research, Vol 13, No. 7, pp. 893-904.

Grant, R. (1991) 'The resource-based theory of competitive advantage: implications for strategy formulation', California Management Review, Vol. 33, pp. 114-135.

Grosse, B., Sargis, C. and Sprimon, P. (2001) Les frontières de l'entreprise: opérationalisation dans le cadre d'une stratégie d'externalisation, Working Paper, Faculté des sciences de l'administration, Université Laval, Québec. 
Grum, A. and Hesse, R. (1983), 'It's the process not the product (most of the time)', Interfaces, Vol. 13, pp. 89-93.

Hamel,G. and Heene, A. (1994) Competence based competition, the strategic Management Series, Chichester: John Wiley \& Sons.

Julien, P., R. Jacob, and L. Raymond. (1998) 'New network technologies for SMEs: toward a meta-organisational learning system', in McCarthy, I.P. and Ridgway, K. (eds.), Proceedings of the First International Conference for Stimulating Manufacturing Excellence in Small \& Medium Enterprises, Sheffield, UK, 20-22 April, pp. 317-27.

Koniger, P. and Janowitz, K. (1995) 'Drowning in information, but thirsty for knowledge', International Journal of Information Management, Vol. 15, No. 1, pp. 516.

Leseure, M., Bauer, J., Birdi, K., Neely, A. and Denyer, D. (2004). "Adoption of promising practices: a systematic review of the evidence", International Journal of Management Reviews, Vol 6, No. 3/4, pp. 169-190.

McIvor, R. (2000) 'A practical framework for understanding the outsourcing process', Supply Chain Management: An International Journal, Vol. 5, pp. 22-36.

Owen, L., Goldwasser, C., Choate, K., and Blitz, A. (2008) 'Collaborative innovation throughout the extended enterprise', Strategy \& Leadership, Vol. 36, No. 1, pp. 3945 .

Poole, M. and Van de Ven, A.. (1989) "Using paradox to build management and organization theories", The Academy of Management Review, Vol. 14, No. 4, pp. 562578.

Prahalad, C. and Hamel, G. (1990) 'The core competence of the corporation', Harvard Business Review, July-August, pp. 79-91.

Probert, D. (1996) 'The practical development of a make or buy strategy: the issue of process positioning', Integrated Manufacturing Systems, Vol. 7, pp. 44-51.

Sandelowski,M., Docherty, S., and Emden. C. (1998) 'Qualitative meta-synthesis: Issues and techniques', Research in Nursing and Health, Vol. 20, No. 4, pp. 365-371.

Saunders, M., 1997, Strategic Purchasing and Supply Chain Management, London: Pitman.

Schary, P. and Skjott-Larsen, T. (2001) Managing Global Supply Chain, Copenhagen: Copenhagen Business School Press.

Siau, K. And Long, Y. (2005) 'Synthesizing e-government stage models - a metasynthesis based on meta-ethnography approach', Industrial management and Data Systems, Vol. 105, No. 4, pp. 443-458.

Thomas, D. (2003). A General Inductive Approach for Qualitative Data Analysis, www.health.auckland.ac.nz/hrmas/Inductive2003.pdf.

Tranfield, D., Denyer, D. and Smart, P. (2003) 'Towards a methodology for developing evidence-informed management knowledge by means of a systematic review', British Journal of Management, Vol. 14, pp. 207-222. 
Venkatesan, R. (1992) 'Strategic sourcing: to make or not to make', Harvard Business Review, November-December, pp. 89-107.

Weick, K. (1979). The Social Psychology of Organising, New York: McGraw Hill.

Welch, J. and Nayack, P. (1992) 'Strategic sourcing: a progressive approach to the make or buy decision', Academy of Management Executive, Vol. 6, pp. 23-31.

Wickham, S. (1996) 'Scénarios de contractions rentables', Gestion 2000, Vol. 12, pp. 95-104.

Williamson, O. (1975) Markets and Hierarchies, New York: Free Press.

Williamson, O. (1985) The Economic Institution of Capitalism: Firms, Markets and Relational Contracting, New York: Free Press. 

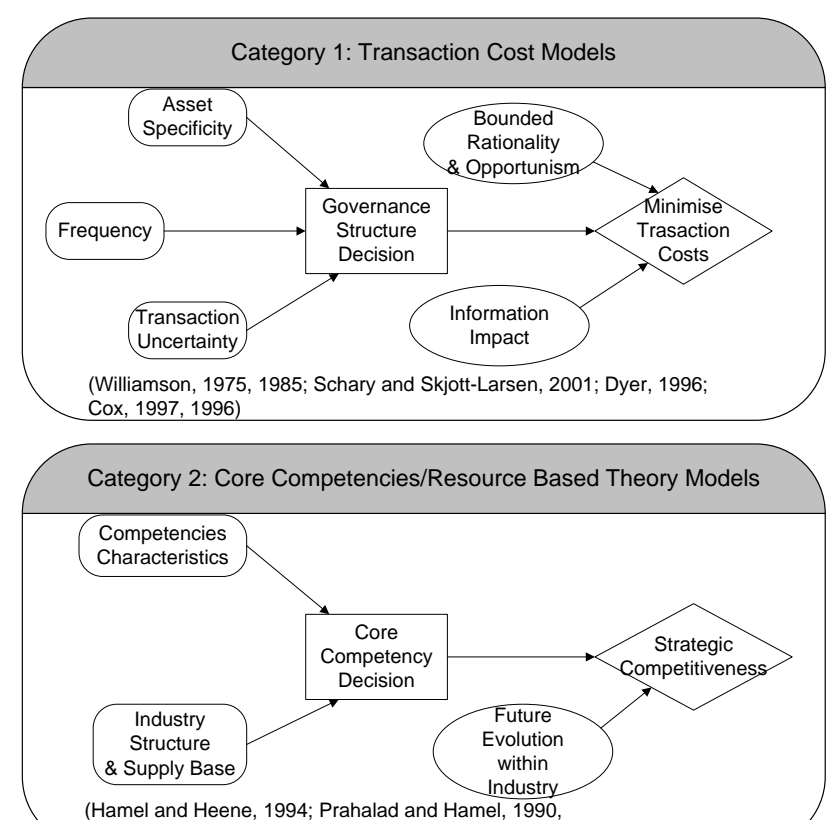

\begin{tabular}{l} 
(1994; Barney, 1991; Grant, 1991; Collis, 1991; Welch and Nayak, 1992) \\
\hline
\end{tabular}

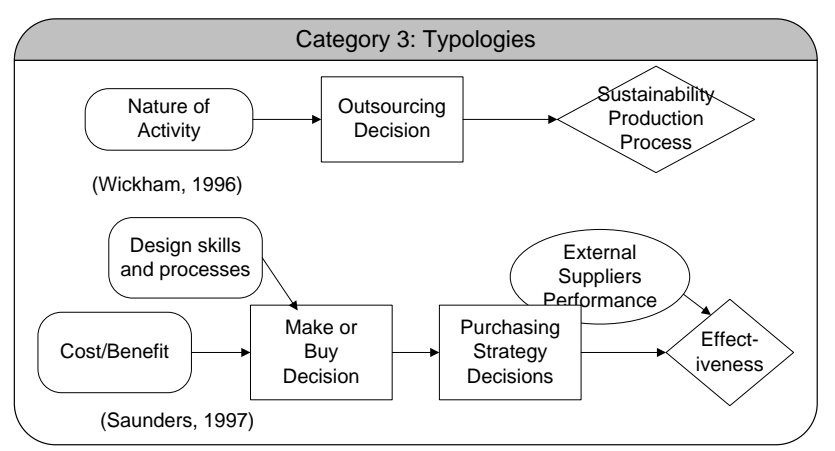

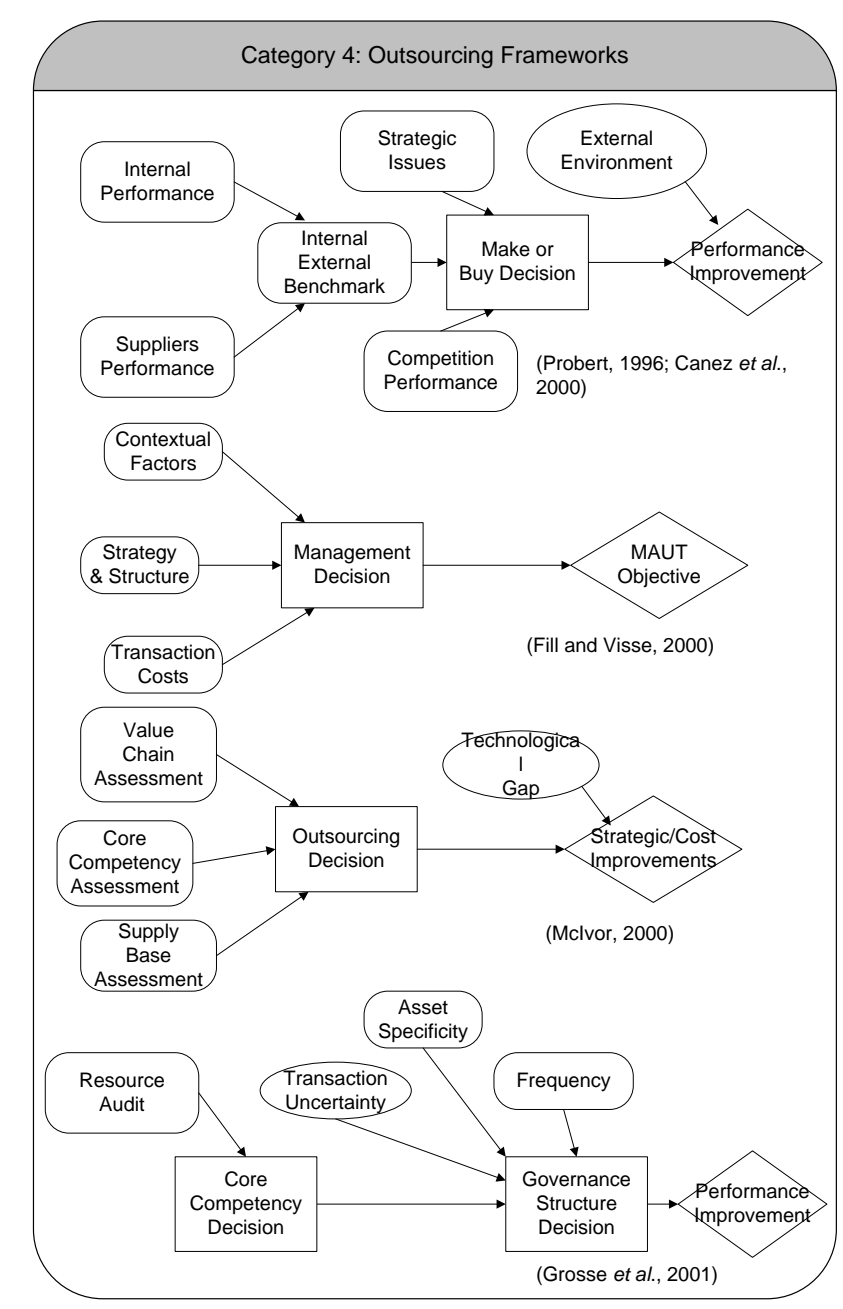

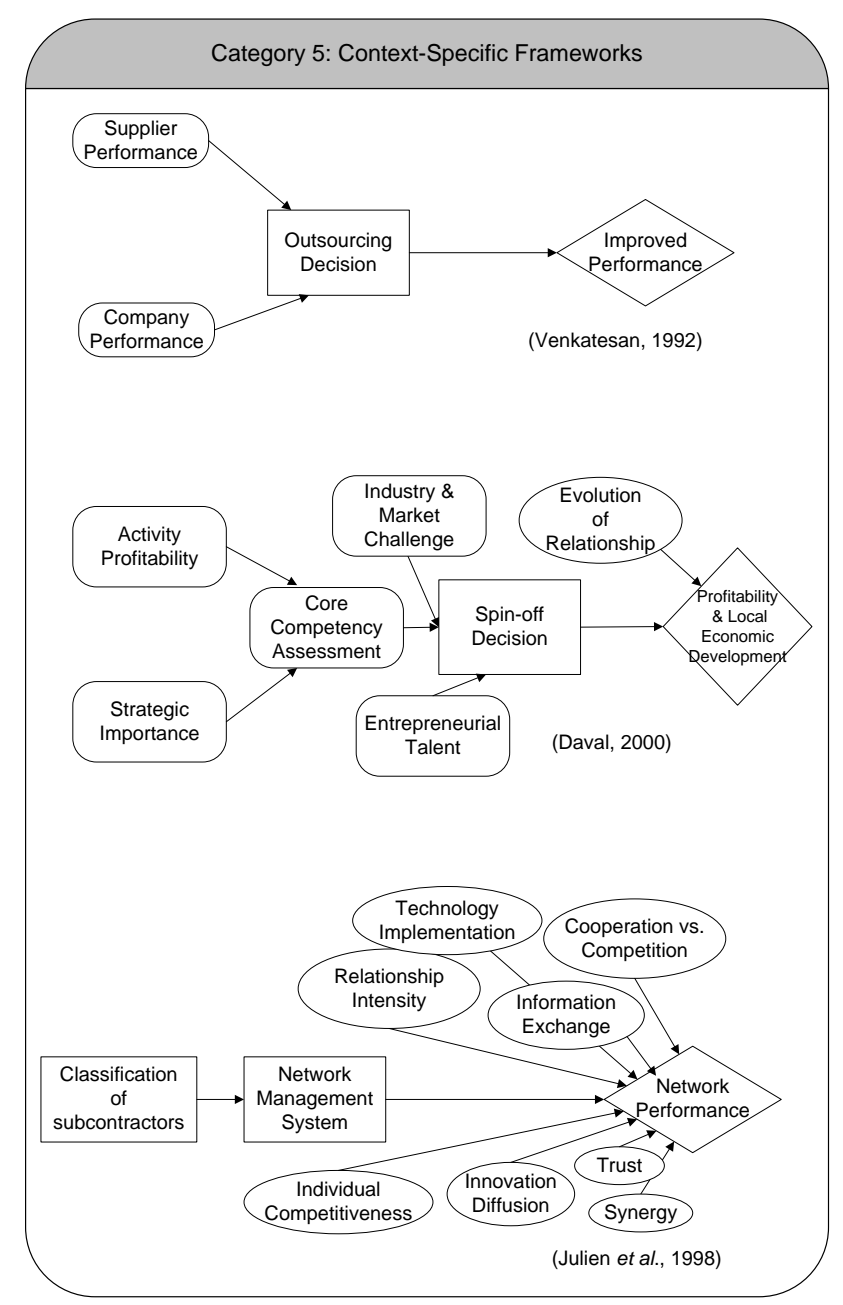

Figure 1. Classification of Influence Diagrams Found in the Literature Review 


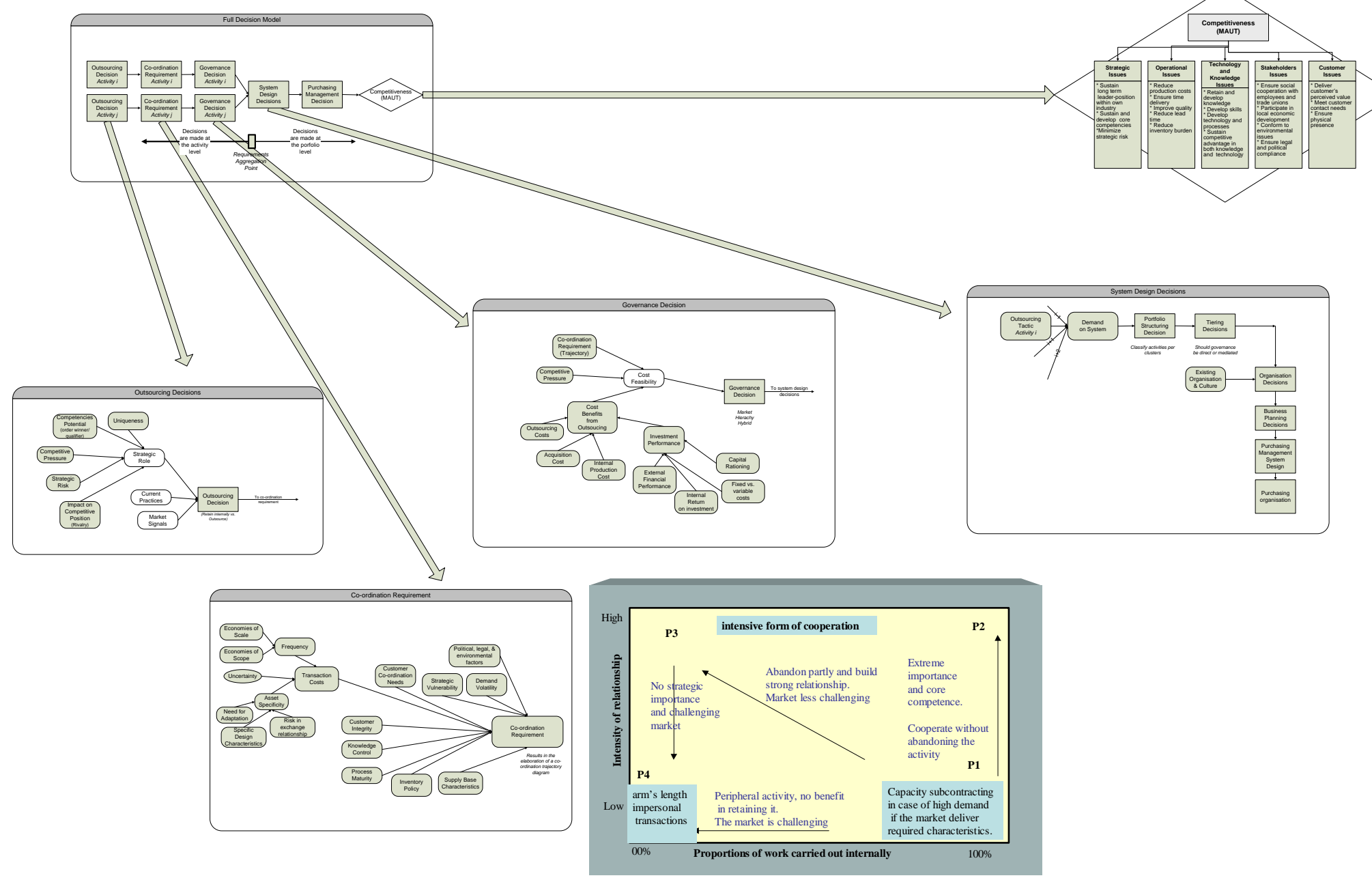

Figure 2. Decision Model 


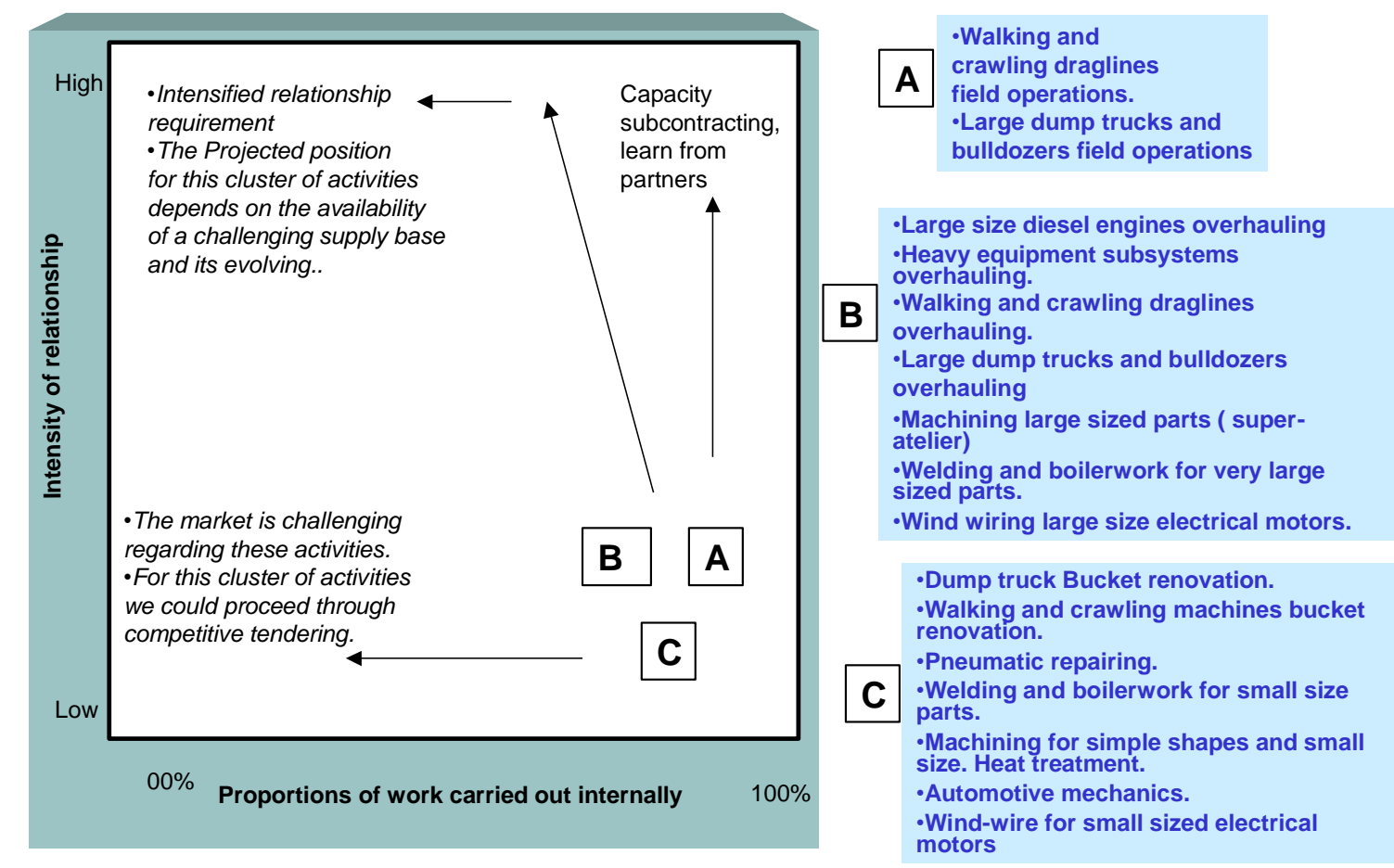

Figure 3. Example of Model Testing. 